\title{
Pedagogías desde la diversidad cultural: una invitación a la investigación colaborativa intercultural
}

Zayda Sierra*

\section{Resumen}

A través de distintas reflexiones y preguntas, producto de distintas experiencias y proyectos en contextos culturalmente diversos, este artículo es una invitación a profundizar de manera colaborativa en las distintas pedagogías que coexisten en el contexto de América Latina (ancestrales, opresivas y coloniales, de resistencia, críticas, creativas, de-coloniales, de la Madre Tierra), lo cual nos permita replantear la herencia colonial y eurocéntrica de la formación docente que todavía prevalece en las facultades de educación. De allí construir propuestas educativas más creativas y pertinentes a los contextos locales - sin perder la perspectiva histórica global -, propuestas que fortalezcan el reconocimiento a la diversidad cultural, el sentido de comunidad y la capacidad de generar alianzas interculturales hacia una existencia en el planeta justa, equitativa y en equilibrio con la naturaleza.

Palabras clave: Educación-América Latina. Diversidad cultural-América Latina. Docentes-Formación-América Latina.

\footnotetext{
* Licenciada en Educación Historia-Filosofía, Universidad de Antioquia (Colombia); M.A en Educación Infantil, The University of Iowa y Ph. D. en Psicología Educativa, The University of Georgia (Estados Unidos). Exbecaria Fulbright. Fundadora del Grupo de Investigación Diverser y profesora titular de la Facultad de Educación de la Universidad de Antioquia.
} 


\section{Presentación}

Las reflexiones que se presentan en esta ponencia ${ }^{1}$ surgen al interior de uno de los países con mayor diversidad cultural, geográfica y biológica del mundo, pero al mismo tiempo con uno de los conflictos armados más agudos, producto de profundas y dolorosas desigualdades económicas y sociales, heredadas de una tradición colonial pavorosamente extractiva y depredadora que pone hoy en riesgo la abundancia de sus fuentes de agua y fertilidad de sus suelos. Inconformes con esta situación, y desde experiencias y contextos culturales diferentes, en el Grupo de Investigación Diverser nos ha unido el esfuerzo de repensar la educación dominante, de carácter competitivo, individualista y conformista, orientada hacia la mera capacitación laboral, para contribuir con la búsqueda de alternativas educativas solidarias, creativas y colaborativas, hacia una mayor justicia social y en defensa de la diversidad de la vida en el país y el planeta.

Las universidades en Colombia - y en particular las facultades de educación - difícilmente han venido respondiendo, en la formación de sus futuros profesionales y docentes, al carácter pluricultural de la nación que finalmente fuera reconocido en la reforma constitucional de 1991, resultado de años de lucha por diferentes movimientos sociales. En estas instituciones todavía se asume el currículo de manera homogénea y hegemónica, confundiéndose la igualdad (en el acceso a los centros educativos, sin cuestionar objetivos y contenidos de programas) con la equidad (el reconocimiento en el currículo de saberes y prácticas de diversos grupos poblacionales, cuyos derechos han sido y siguen siendo vulnerados). De esta manera, las universidades y las facultades de educación han venido contribuyendo, consciente o inconscientemente, con la violencia que ha caracterizado nuestra historia desde la conquista europea, en particular, la violencia epistémica (CASTRO-GÓMEZ, 2000), al ignorar, invisibilizar o negar otras maneras de ser, pensar y habitar el mundo, privilegiando y legitimando aquellos conocimientos que benefician a quienes detentan el poder político, económico y social.

Mediante reflexiones críticas sobre el quehacer autoritario de la academia y la ciencia, que compartimos con pensadoras y pensadores críticos del Norte y del Sur, de Occidente y Oriente ${ }^{2}$, hemos venido explorando otras posibilidades de pensar la actividad pedagógica, más conectadas con la vida 
y la capacidad creadora de personas, grupos y pueblos, más comprometidas con una existencia justa y digna de toda la población.

Ello nos ha implicado dialogar a través de varios proyectos investigativos con un país profundamente diverso, cuyas problemáticas exigen soluciones diferentes. ¿Qué es propio de cada pueblo o cultura, qué nos es común? son preguntas que emergen en este diálogo con poblaciones campesinas, indígenas, afrocolombianas y urbanas; preguntas todavía en construcción, pero que encontramos son solidarias con búsquedas similares en otras partes del mundo, hacia una escuela y vida en comunidad menos castradora, hacia una existencia en el planeta más significativa y en equilibrio con la naturaleza. Pedagogías desde la diversidad cultural es una agenda investigativa que surge de este proceso, y nos permite comprender mejor las dificultades que enfrentan niñas, niños, jóvenes, sus familias y comunidades, así como maestras y maestros o líderes y lideresas que viven en contextos de marginación y opresión, para construir colectivamente propuestas educativas más adecuadas y pertinentes a sus necesidades y expectativas, más respetuosas con la vida en el planeta.

Estas reflexiones se concretan en la actualidad en el esfuerzo conjunto entre la Organización Indigena de Antioquia-OIA (que representa a los pueblos originarios de la región: Kunatule, Embera y Senú) y la Universidad de Antioquia (segundo centro de educación superior pública en Colombia), para la creación de una propuesta de formación orientada específicamente a esta población, hasta entonces ausente de las instituciones universitarias por dificultades en el acceso y la pertinencia de los programas. Atendiendo a la solicitud de la OIA, y después de romper varias barreras institucionales, logramos la creación del Programa de Educación Indígena en la Facultad de Educación (agosto de 2005) con la consecuente vinculación de un primer profesor indígena de tiempo completo para su coordinación. Desde entonces venimos avanzando de manera conjunta y participativa la construcción curricular de la Licenciatura en Pedagogía de la Madre Tierra, un nuevo programa de pregrado que contribuya con el fortalecimiento de los procesos organizativos y la pervivencia cultural de los pueblos indígenas, el cual actualmente se hace realidad en formato Diploma con 110 participantes, entre líderes, bachilleres y docentes indígenas de la región. Dicho programa ofrecerá en los dos últimos años, la opción de profundizar en uno de los siguientes énfasis de formación: 
- salud comunitaria intercultural;

- lenguajes e interculturalidad, y

- ordenamiento y autonomía territorial.

Pensar el componente pedagógico de este nuevo programa nos viene exigiendo una aproximación muy diferente a la tradición eurocéntrica predominante en nuestras Facultad de Educación para los otros programas de formación docente, que privilegia una historia lineal del maestro o la infancia ("Grecia, el Medioevo, la modernidad") y a la escuela como el único modo de transmisión/conservación/recreación del saber ${ }^{3}$; para preguntarse en cambio sobre la diversidad de procesos educativos de los pueblos ancestrales de Abya Yala (América), el impacto de la conquista y colonización europea en sus vidas, los procesos de resistencia tanto de las culturas originarias como de otros grupos sociales igualmente afectados por la colonización, la modernidad y la actual economía global de mercado, así como las búsquedas creativas entre distintos colectivos del planeta, que comparten el sueño de un mundo mejor.

Esta propuesta recoge también reflexiones del diálogo con participantes de dos programas de posgrado de los cuales hemos sido también artífices: la Maestría en Educación, énfasis en Pedagogía y Diversidad Cultural (abierta en 2002) y el Doctorado en Educación, línea Estudios Interculturales (abierta en 2004). Igualmente, recoge temas de conversaciones con representantes de organizaciones afrodescendientes, con quienes venimos impulsando la creación del Programa de Estudios Afrocolombianos en la Facultad de Educación, para lo cual la Universidad dio un paso importante al abrir convocatoria de una plaza docente de tiempo completo para un/a profesional de este grupo étnico (diciembre de 2008).

Quien escribe estas reflexiones, a modo de relatoría de un proceso conjunto que nos llena de esperanza, se debate ante aquellas voces que cuestionan y sospechan de la colaboración activa de personas de la academia con las luchas de sectores históricamente oprimidos. Son las acciones y el pensamiento de las personas, no su origen social, escolaridad o color de piel, las que deben juzgarse. Romper las secuelas de una historia colonial violenta que nos ha escindido en jerarquías, exige que trascendamos prejuicios y aunemos distintos corazones, saberes e inteligencias. Es responsabilidad de cada uno de nosotros - en mi caso, desde una universidad pública- ser arte 
y parte de la tarea por construir un mundo no excluyente, en el que todas $\mathrm{y}$ todos tengamos posibilidades de una vida digna.
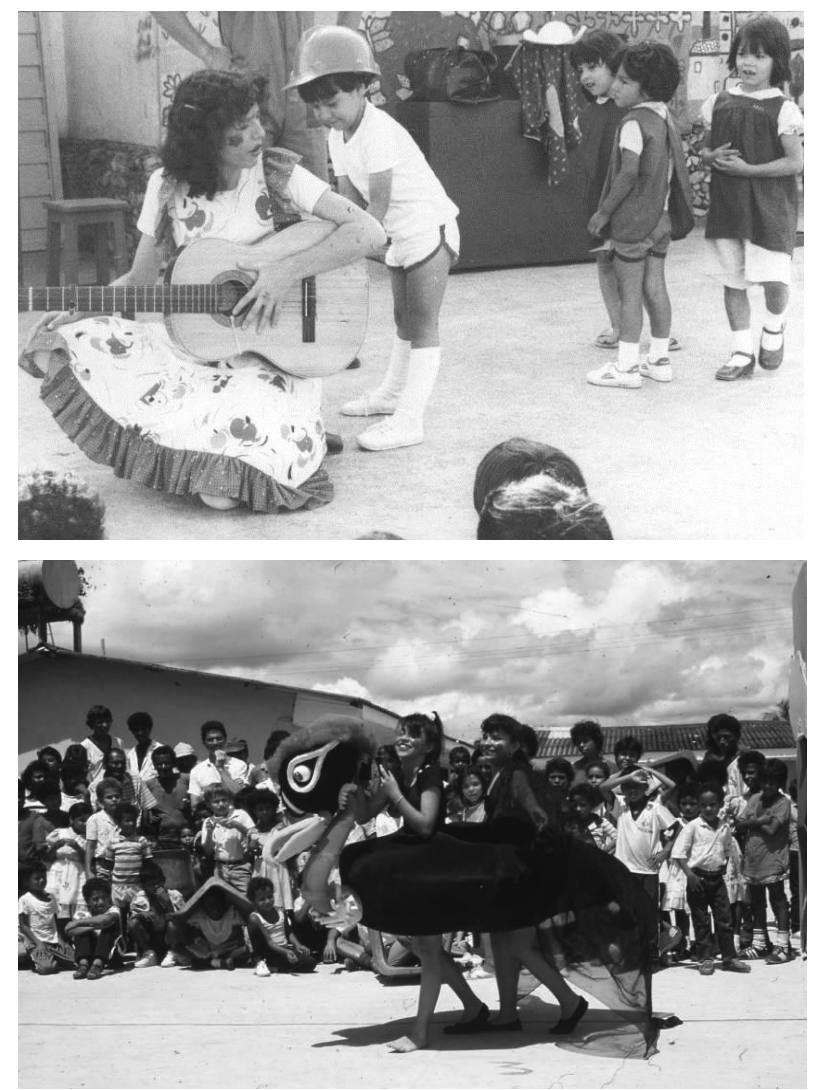

Figuras 1 y 2: La autora como actriz y directora de teatro infantil: (Izquierda) "Cantar y contar", en Jardín de Bienestar Familiar, Medellín. Foto: Jairo Flórez, 1983. (Derecha) "El país pequeñito de los sueños perdidos", Teatro Bambalinas de la Universidad de Antioquia, en región minera de El Bagre - Antioquia. Foto: Zayda Sierra, 1994.

\section{Algunos referentes para este diálogo}

En nuestro medio usualmente se confunden los conceptos de "educación", "escolaridad" y "pedagogía". En esta reflexión asumiremos que 
la educación nace con la humanidad. Sería la manera como cada pueblo del mundo crea y recrea saberes, artes y técnicas que les permiten el disfrute de su entorno y su supervivencia, de allí la importancia de transmitirla a las nuevas generaciones.

Cada generación aprende y hace uso de las tradiciones y herramientas materiales, intelectuales y espirituales provistas por las generaciones anteriores, que simultáneamente transforma al aplicarlas (ROGOFF, 1993). La escolaridad sería entonces una entre tantas formas de educación, pero presentada por la sociedad moderna occidental como si fuera la única y verdadera educación.
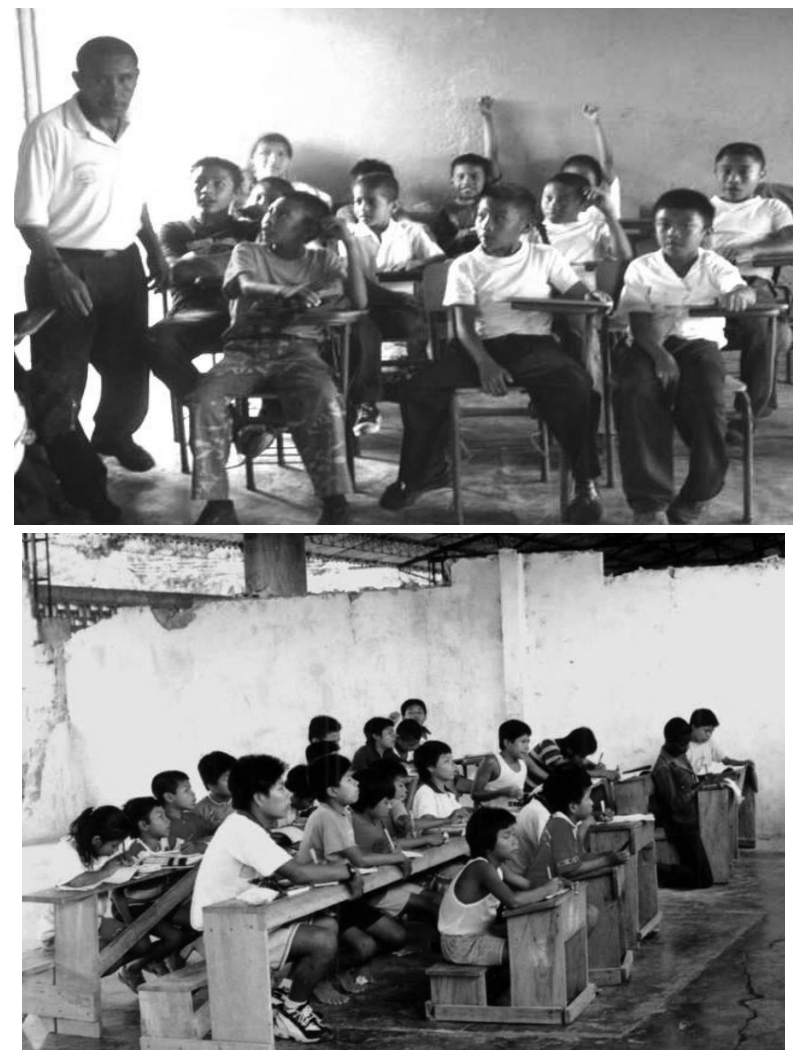

Figuras 3 y 4: La uniformidad de la experiencia escolar. (Izquierda) Pueblo Kunatule, Caimán Bajo, Antioquia). Foto: David Sierra, 2008. (Derercha) Pueblo Embera (Alto Baudó, Chocó). Foto: Pascacio Chamorro, 2001. 
Quienes nos interesamos por la pedagogía nos preguntamos por los objetivos y la manera cómo se da la educación en distintos tiempos y espacios (históricos, sociales, comunitarios, políticos, familiares, escolares, personales), para reafirmar, cuestionar o transformar saberes y prácticas; sólo que la pedagogía impuesta desde la expansión europea ha privilegiado la reclusión de los aprendices en recintos cerrados o escuelas, legitimándolos como los únicos espacios propios para la educación mientras ha deslegitimado otros espacios y momentos educativos (en la familia, fiestas, celebraciones, oficios $\mathrm{u}$ otras actividades de una comunidad). Un ejercicio importante a realizar en el futuro será profundizar qué significan estas palabras en distintas lenguas, si nos sirven como puente comunicativo para extrapolar experiencias o si debemos re-considerarlas.

La interculturalidad es también tan antigua como la historia humana; distintos pueblos han aprendido unos de otros y han dado distinta valoración a sus conocimientos. Desafortunadamente, estas interacciones entre pueblos y culturas no siempre han sido de intercambio equitativo o simétrico; muchos pueblos han impuesto sus saberes y conocimientos presentándolos como superiores, con el afán de asimilar o exterminar a otras culturas, apropiándose así de sus bienes y territorios. El diálogo y la investigación intercultural no pueden pensarse ingenuamente al margen de estos distintos contextos de interacción.

Pedagogias desde la diversidad cultural nos permite preguntarnos, desde el contexto de América Latina, por el significado de saberes y prácticas educativas de distintos pueblos y sus intercambios con otros pueblos en distintos momentos históricos, para -desde esta investigación colaborativa intercultural- contribuir con la toma de conciencia sobre los procesos educativos en las etapas de florecimiento de la propia cultura; de intercambio u opresión de unos pueblos con otros; de resistencia a la imposición de una cultura dominante, como la europea; de reflexión crítica, búsqueda y creación de posibilidades de convivencia respetuosa. 


\section{Pedagogías Ancestrales}
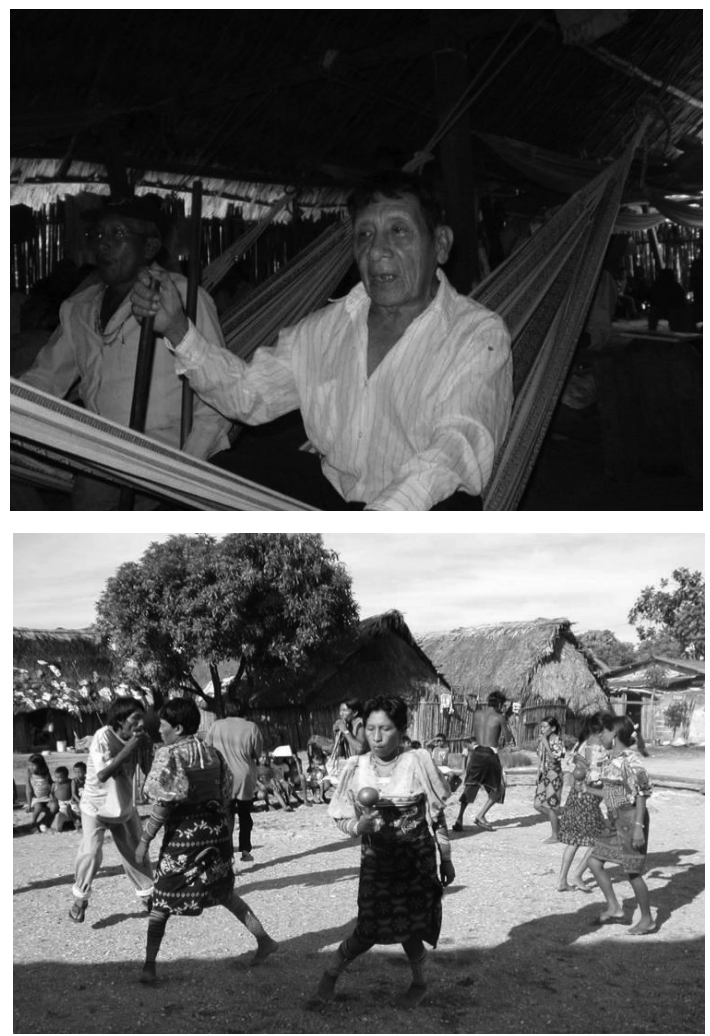

Figuras 5 y 6: Pedagogías Ancestrales. (Izquierda) Memoria oral con Sakla Victor Peláez (Caimán Nuevo) y (Derercha) danza tradicional (Comarca Kuna Yala). Pueblo Kuna Tule, Diploma convenio Proyecto de Educación Bilingue Intercultural (Panamá) y Universidad de Antioquia (Colombia). Fotos: Zayda Sierra, 2006.

"[... Jentre nosotros no existe la escritura. No escribimos todo el conocimiento sino que se aprende es a nivel visual, con el tacto, con la escucha, con el dolor. El estudio que nosotros sabemos desde el interior, de la parte tradicional, se hace de dia y de noche. O sea, que de día se aprende la medicina, las botánicas, porque uno tiene que ir al monte a escuchar los olores de las plantas, a ver los colores de las plantas, a ver la casa de las plantas... 
¿De noche, qué se aprende? Los cantos terapéuticos, o sea el canto al cuarzo, el canto al cacao, el canto al ají picante se aprende de noche, no de día. Entonces, por lo tanto, día y noche uno está ocupado..."

"Una universidad, asi sea propia, no deberá reemplazar la educación ancestral ni a nuestros sabios y sabias ni a su saber milenario, que no han necesitado de edificios ni escuelas para enseñar nuestro pensamiento y conocimientos. Nuestra universidad está en nuestros territorios, en la vida comunitarias."

Contrario a las enseñanzas de los currículos de ciencias sociales, todavía vigentes en los centros de educación oficiales, los saberes y prácticas ancestrales de los pueblos originarios de Abya Yala no son asunto del pasado, de una "etapa precolombina" sino que siguen vivos; sólo que algunos pueblos están en condiciones más vulnerables para mantener su pervivencia, producto de siglos de usurpación de su territorio e intervención colonial en la educación. Algunos botánicos, por ejemplo, ya no cuentan con los montes sagrados o no cuentan con aprendices pues la institución escolar les retiene niños, niñas y jóvenes la mayor parte del día. Así nos explicaba un estudiante universitario indígena:

“Tengo un tío que es Jaibaná (médico ancestral). El me eligió para aprender su saber, pero no he podido salir con él a andar el monte por varias semanas pues se me afectan los estudios en la universidad. Me preocupa, pues él ya está muy viejo y se puede morir ${ }^{6} . "$

Los pueblos afrodescendientes y raizales resaltan a su vez saberes y prácticas ancestrales en distintos campos de la vida, que lograron pervivir durante los años de esclavitud y cimarronaje, y que se fueron recreando durante ańos y años de intercambio con nuevas geografías, plantas, climas y culturas, lo cual viene desde hace varios años siendo motivo de estudio etnográfico, literario y documental (ROJAS, 2004).

La ruptura que genera la institución escolar con los procesos educativos propios es un malestar central que expresan ancianos y ancianas de distintas comunidades indígenas, por ello su rechazo a que las generaciones más 
jóvenes vayan a la escuela o a la universidad; puesto que existe una fuerte presión sobre las familias más jóvenes para enviar sus hijos e hijas a aprender la lengua y cultura dominante, pues se espera que así las condiciones de vida sean menos adversas (SIERRA, 2005), es necesario promover cambios sustanciales en la estructura y contenidos de la escolaridad preescolar, básica, secundaria y universitaria actual.

Una mayor comprensión de las pedagogías ancestrales permitirá, por ejemplo, generar en los distintos programas curriculares propuestas que permitan a estudiantes de diversos grupos étnicos su participación en rituales y otros procesos comunitarios, para lo cual es necesario flexibilizar calendarios y diseñar tareas relacionadas con sus contextos de vida. Igualmente promover en estudiantes indígenas y afrodescendientes la investigación de los procesos educativos propios, complementando este conocimiento con saberes y prácticas ancestrales de otros pueblos y comunidades.

Para las personas mestizas, reconocer estos saberes (negados, ignorados e invisibilizados en sus ańos escolares) les permitirá una mayor comprensión de la diversidad cultural de su país y sensibilidad hacia sus hermanos y hermanas afro e indígenas, para así apoyar sus luchas y reivindicaciones.

\section{Preguntas para la reflexión y la investigación}

- ¿Cómo se enseñaban y enseñan, se aprendían y aprenden, los saberes de los pueblos originarios y afrodescendientes de Colombia y Abya Yala, en distintos campos del conocimiento (gobierno, manejo territorial, clima y estaciones, caza y pesca, cosechas, riego, tejidos, culinaria, artes y artesanía, otros oficios, crianza, historia, lengua y pensamiento, arquitectura, salud, espiritualidad, entre otros)?

- ¿Qué caracteriza a sabedores y aprendices en estos distintos campos de conocimiento? ¿Cuáles son los espacios privilegiados para la enseñanza/aprendizaje? ¿Qué etapas se requieren atravesar? ¿Cómo se evalúa el avance en el saber?

- ¿Qué requiere la pedagogía ancestral para su pervivencia? ¿Qué debemos retomar de la pedagogía ancestral para nuestro quehacer educativo hoy, tanto en el mundo indígena como no indígena? 


\section{Pedagogías coloniales, opresoras y autoritarias}

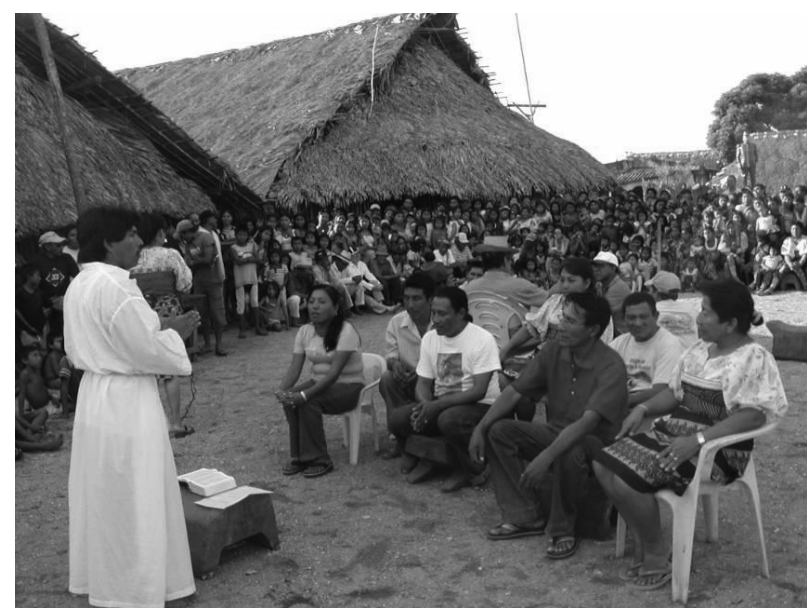

Figura 7: Pedagogías coloniales y opresivas. Juego dramático sobre la influencia de las misiones en la pérdida de la lengua original. Pueblo Kuna Tule, Diploma convenio Proyecto de Educación Bilingue Intercultural (Panamá) y Universidad de Antioquia (Colombia). Foto: Zayda Sierra, 2006.

A pesar de innumerables críticas, el currículo oficial en América Latina todavía presenta la llegada a América de españoles y portugueses como un "encuentro de dos mundos" mientras privilegia durante todo el período escolar la lengua, la religión y demás saberes heredados de la "madre patria". A su vez, la academia universitaria olvida que el saber científico en América, aún después de la independencia, no se desprendió de la manera europea de ver el mundo y construir el conocimiento, sino que, por el contrario, mantuvo la apropiación colonial de saberes de las culturas nativas mientras las descalificaba como ignorantes y no civilizadas (NIETO, 2000).

Desde la crítica latinoamericana a la modernidad y la colonialidad, Fernando Coronil nos invita a descentrar la historia que nos han contado y reconocer que el fortalecimiento de Europa no hubiese sido posible sin el aporte de la "periferia", tanto como fuente principal de riquezas naturales como de trabajo barato y así ver la relación constitutiva entre capitalismo y colonialismo. "El colonialismo es el lado oscuro del capitalismo europeo", afirma este autor. 
Además de aportar mano de obra, productos agrícolas y recursos minerales, las colonias "le presentaron a Europa una variedad de culturas en contraposición a las cuales Europa se concibió a sí misma como el patrón de la humanidad - como portadora de una religión, una razón y una civilización superiores encarnadas por los europeos." (CORONIL, 2000, p. 93).

La colonialidad está inserta en la misma constitución de una modernidad que se nos presenta bajo el ropaje de una sociedad liberal, supuestamente más avanzada y progresista, pero que no puede enmascarar su carácter colonial, hegemónico e imperial, el cual se sigue expresando en distintas esferas de nuestra vida, en los ámbitos del poder, del ser, del saber y la naturaleza (WALSH, 2005, p. 19-23).

Desde tiempos de la Colonia, el modelo pedagógico imperante en los distintos espacios de formación (misiones, colegios, universidades) ha sido el de moldear el pensar y sentir de los habitantes de las regiones o grupos de la periferia bajo unos parámetros establecidos desde la metrópoli, sin mediar interlocución alguna con sus necesidades, identidades e intereses.

Pedagogías coloniales, opresoras y autoritarias invita a reconocer la conquista ibérica de los pueblos de Abya Yala como el momento fundante de dos procesos históricos que no pueden mirarse por separado: la modernidad y la conformación colonial del mundo, esto es, la instauración de la oposición entre el mundo occidental o europeo (concebido como lo moderno, lo avanzado) y los "otros", el resto de los pueblos y culturas del planeta (LANDER, 2000, p. 16).

La escuela será escenario por excelencia para construir esta escisión. Todavía, hacia la primera mitad del siglo XX, la modernización de la escuela en Colombia se caracterizó por una alianza entre religión y biología, esto es, los males intelectuales, morales y sociales del país se explicaron como producto de una raza degenerada, cuyo estado "bárbaro" y "salvaje" era preciso corregir (SÁENZ, 1997), filosofía republicana que no rompió con el pensamiento colonial eurocéntrico, el cual sustentó el proceso de conquista del territorio americano a partir de un permanente menosprecio de sus habitantes (ORGANIZACIÓN NACIONAL INDÍGENA DE COLOMBIA, 2002).

Para comienzos de este siglo, los discursos educativos oficiales se debatían en cómo evitar "la degeneración de la raza colombiana” y cómo "separar al alumno de la masa inmoral y enferma del pueblo para convertirlo en un individuo productivo, amante del trabajo y de la economía... un 
individuo pensado a la imagen y semejanza de los pueblos anglosajones." (SÁENZ, 2001, p. 301). Hoy día, con muy pocas excepciones, la escuela continúa enfatizando la transmisión de saberes uniformes, y en el caso del denominado Tercer Mundo, "de códigos culturales europeos y norteamericanos hegemónicos” (BARBOSA, 2000, p. 142).

El discurso de la interculturalidad que se propone hoy como paliativo a esta historia imperial, no puede construirse sin mirar críticamente los efectos en nuestras vidas de la colonialidad, esto es, debemos examinar cómo largos procesos de asimilación, alienación y aculturación siguen presentes y se manifiestan en prejuicios, autoritarismos y opresiones en nuestra interacción cotidiana en la familia, las aulas escolares, la academia, la vida en comunidad, la sociedad en general.
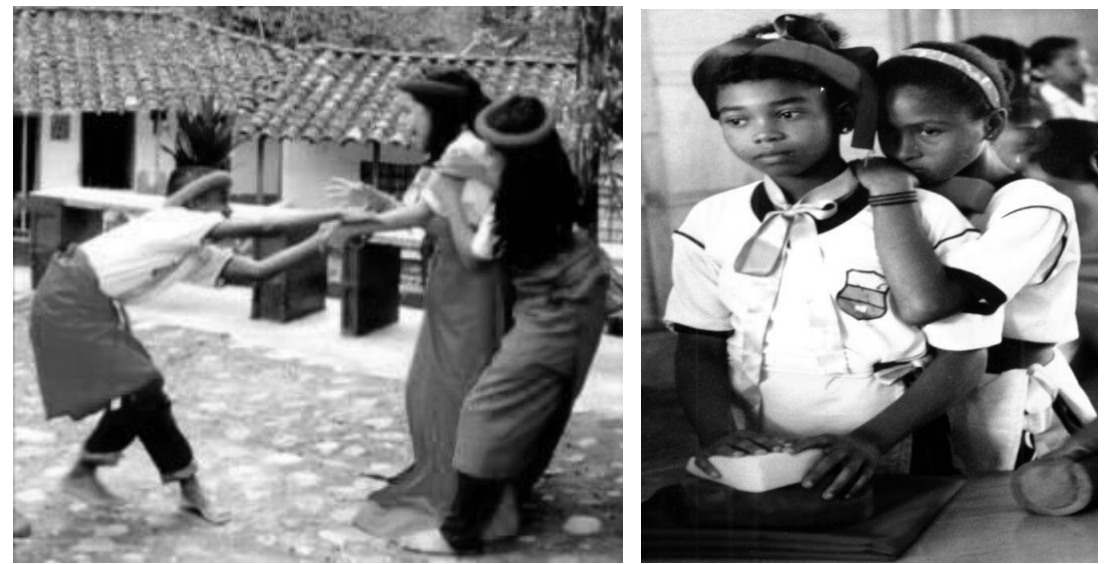

Figuras 8 y 9: Pedagogías coloniales y opresivas. Juego dramático sobre maltrato en la familia y la escuela, por estudiantes de centros educativos de Yarumito (BarbosaAntioquia) y San Onofre (Sucre). Fotos: Zayda Sierra, 2001.

\section{Preguntas para la reflexión y la investigación}

¿Qué saberes y prácticas pedagógicas europeas se impusieron para favorecer la conquista y colonización de los pueblos de Abya Yala y los pueblos esclavizados de África? ¿Cómo se justificó su supuesta superioridad? ¿Qué caracteriza a la educación evangelizadora y doctrinaria? ¿Cómo se sigue manifestando hoy día? 
- Durante el período republicano, ¿qué nuevos modelos pedagógicos llegaron a tierras americanas? ¿Qué significaron las reformas educativas modernas para los pueblos indígenas y afrodescendientes?

- En esta época de economía global de mercado, ¿qué perspectivas se imponen en nuestros sistemas educativos? ¿Por qué se sobrevalora la competencia y el individualismo por encima de la colaboración y la comunitariedad? ¿Cómo impacta la alienación, asimilación y aculturación en la vida personal, familiar, escolar y comunitaria?

\section{Pedagogías de resistencia}
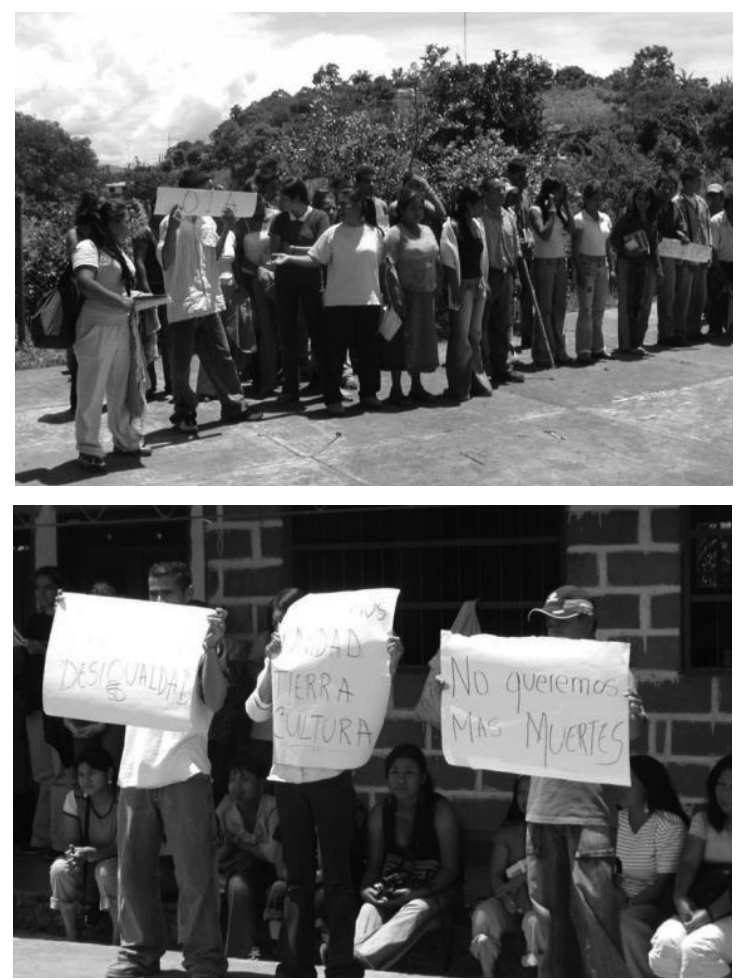

Figuras 10 y 11: Pedagogías de resistencia. Representación teatral del proceso organizativo para la recuperación de tierras de la comunidad Embera Chamí del Resguardo de Karmata Rúa (Antioquia). Dirección artística: Gladis Yagarí. Proyecto: "Creación participativa de propuestas curriculares interculturales". Foto: José Orduz, 2006. 
Este sería el espacio para aprender sobre complejos procesos organizativos de distintos pueblos y grupos sociales - así como de las personas que los han liderado -, no incluidos en la historia y currículo oficial, y que dejan huella en nuestra existencia por las importantes reivindicaciones y transformaciones sociales que proponen (movimientos indígenas, antiesclavistas, feministas, campesinos, de derechos humanos, pedagógicos, entre otros), algunas con propuestas de carácter más reformista, otras más radicales en los planteamientos de una nueva sociedad. Ejemplos recientes a resaltar en el contexto colombiano, por su valentía frente a la respuesta asfixiante del gobierno ante cualquier signo de protesta o diferencia de pensamiento son: la Minga Indígena, el paro de corteros de cańa, las organizaciones por los derechos de las víctimas de los actores armados, los movimientos por los derechos de las mujeres (entre ellos, el aborto), de las diversidades sexuales o de las organizaciones de recicladores por un trabajo digno, entre otros.

Si bien los procesos de resistencia exigen altas dosis de ingenio y creatividad por parte de las personas, grupos o pueblos para luchar contra la opresión y enfrentar la represión, conllevan a su vez el enorme riesgo de quedarse en reacciones coyunturales, que no logran romper el marco referencial o la lógica de quienes dominan. Las expresiones contestatarias, al no obtener respuestas satisfactorias inmediatas, generan agotamiento físico, intelectual y emocional de sus participantes, presentándose fenómenos como la desmoralización, la desmovilización y el abandono de los ideales.

Es por ello que, independientemente de los tiempos de calma o insurrección, se deben procurar espacios continuos de reflexión crítica de las condiciones de vida y la búsqueda permanente de alternativas creativas, para poder enfrentar con mejores elementos cognitivos, afectivos, relacionales y organizativos los tiempos de mayor adversidad. A las pedagogías críticas y creativas les dedicaremos otro espacio más adelante.

\section{Preguntas para la reflexión y la investigación}

- ¿Cómo distintas personas, grupos o pueblos en la región, el país y alrededor del mundo han venido enfrentando la opresión de sectores o culturas dominantes? 
- ¿Qué ha permitido la pervivencia de diversos pueblos y sus culturas, a pesar de penosas condiciones de opresión y marginación?

- ¿Qué se puede aprender para el contexto educativo en la vida personal, familiar, escolar y comunitaria de distintos movimientos de resistencia?

\section{Pedagogías críticas}

Para muchos estudiantes, la enseñanza es la experimentación diaria de formas de interacción en el aula que son irrelevantes en sus vidas, pero también la dura realidad de la discriminación y la opresión que se expresa a través de la vigilancia, el acoso y la expulsión. (GIROUX, 1998, p. 48, 51).

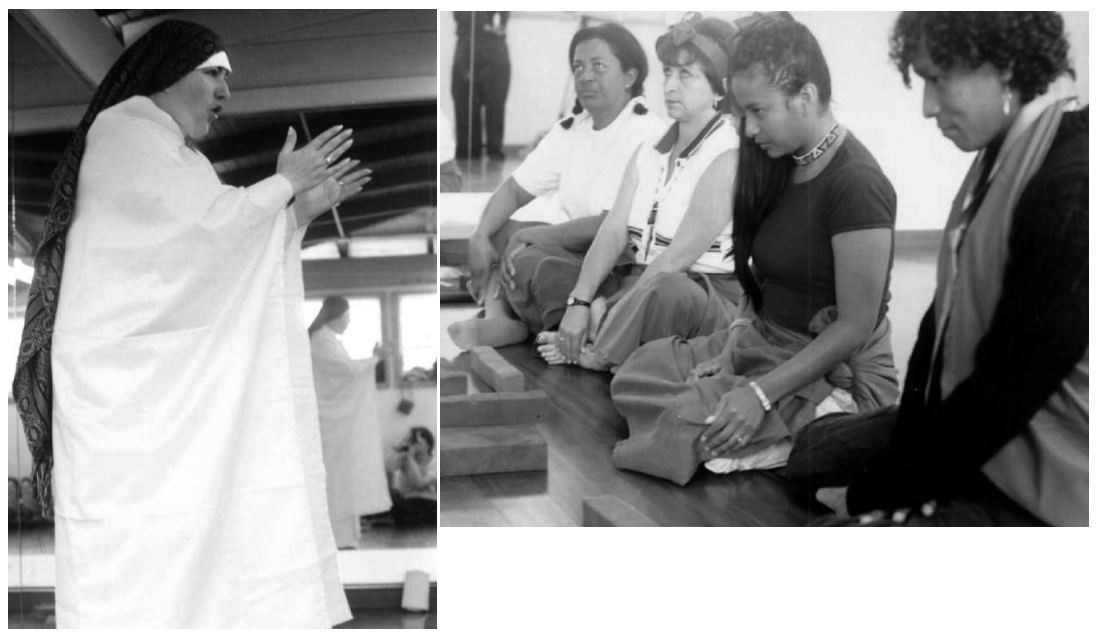

Figuras 12 y 13: Pedagogías críticas. Docentes dramatizan sobre el autoritarismo en la escuela. Proyecto "La representación social a través del juego dramático en niños y nińas de diverso contexto cultural.” Foto: Zayda Sierra, 2001.

La pedagogía critica, retomando a GIROUX (1997, p. 60-61), propone una nueva sociología del currículum, que deje de lado la pretensión ideológica de estar libre de cualquier clase de valor, lo que invita a maestros y maestras a desarrollar una sensibilidad crítica que sea extensión de su conciencia 
histórica. Esto es, reconocer que la realidad no es estática, sino que por el contrario, es algo que debe cuestionarse y analizarse continuamente, de esta manera contribuir a desenmascarar las relaciones de dominación y propender por la emancipación de la sensibilidad, de la razón y la imaginación en todas las esferas de la vida.

Para ello son necesarias herramientas investigativas de carácter histórico-social, que cuestionen la visión de las culturas como entidades delimitables o totalidades independientes y, por el contrario, ayuden a ver su conexión y articulación con procesos históricos no sólo locales sino globales, no sólo de corto alcance sino de larga duración. Herramientas que permitan "aprender a ver cómo existen sistemas de estratificación social que fragmentan la población en distintos grupos y clases, a considerar las contradicciones internas de una cultura y la especificidad de un grupo respecto a otro dentro del propio grupo, y a develar las distintas formas de poder y mecanismos de dominación" (COMAS D’ARGEMIR, 1996, p. 110).

La pedagogía crítica cuestiona el carácter homogéneo y hegemónico de la escuela moderna y reconoce en cambio a alumnos y alumnas como portadores de diferentes memorias sociales, con el derecho a hablar y a representarse en la búsqueda del conocimiento y la autodeterminación. La pedagogía crítica se nutre de epistemologías marxistas, feministas, antiracistas y postcoloniales, que develan desde sus distintas ópticas la profunda conexión entre cultura, saber y poder, lo cual significa un alejamiento de las narrativas dominantes eurocéntricas, el conocimiento disciplinario y el cientificismo, herencia del legado modernista, para ocuparse de la gran diversidad de fenómenos sociales y culturales que caracterizan al mundo actual (GIROUX, 1998).

El cuestionamiento que la pedagogía crítica hace al carácter asimilativo y aculturizante de la escuela permite visualizar otros modelos de educación intercultural más equitativos, biculturales, pluriculturales, de transformación y reconstrucción social. En el contexto de América Latina, el brasileño Paulo Freire y el colombiano Orlando Fals Borda ofrecen importantes herramientas conceptuales y metodológicas para abordar de manera crítica y participativa la producción de conocimiento con comunidades marginadas, hacia la transformación de las condiciones de opresión que afectan su existencia. 


\section{Preguntas para la reflexión y la investigación}

- ¿Cómo identificar de manera continua en el currículo, supuestamente neutral y universal, ideologías autoritarias, racistas, patriarcales, sexistas y clasistas?

- ¿Cómo facilitar que expresen su voz aquellas personas y colectividades que han sido silenciadas?

- ¿Qué podemos aprender para nuestros contextos de vida, de propuestas pedagógicas anti-racistas, feministas y pluriculturales?

\section{Pedagogias creativas}

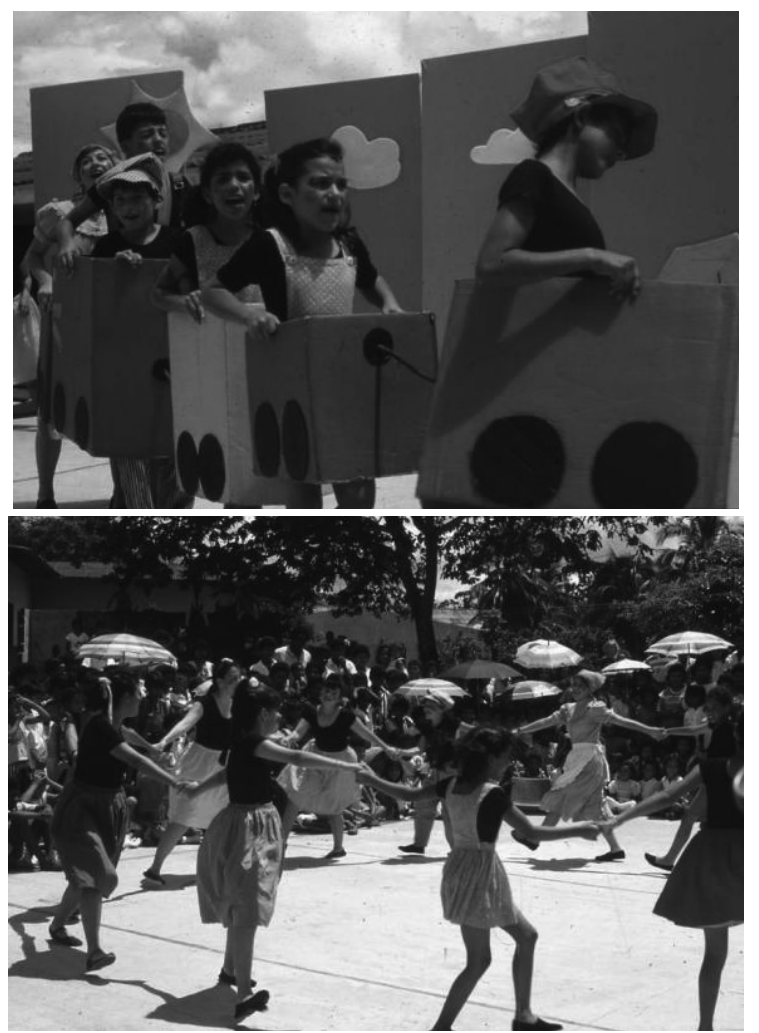

Figuras 14 y 15: Pedagogías creativas. Teatro Infantil Bambalinas de la Universidad de Antioquia. "El país pequeñito de los sueños perdidos" en corregimiento Puerto Claver, región minera de El Bagre. Dirección artística y fotos: Zayda Sierra, 1988. 
Un aspecto cultural común a los distintos grupos humanos son los cantos de cuna; sin embargo, cuánta diversidad y creatividad en ellos, cuántos juegos de palabras para espantar los miedos y dar alegría a la existencia. ¿Qué significa esta capacidad poética? Veamos esta canción que recoge los poemas de Emilio Ballagas (cubano) y Gregorio Castañeda (colombiano) (en Sierra, 1994):

Dormiti mi nengre

dormiti nengrito

caimito y merengue

merengue y camito.

Mi chiribicoco chiribicoquito

caimito y merengue

merengue y caimito.

Cuándo grande seas,

que un día será,

te irás, iquién lo duda!

solito a viajar, y mamá la vieja

se pondrá a cantar

a cantar canciones

que ya no oirás

con nieve de espuma,

con sol y con sal,

con sal de las olas,

con sol de la mar.

Dormiti mi nengre

dormiti nengrito

caimito y merengue

merengue y camito.

Mediante la capacidad de representar en imágenes la realidad y comunicar dichas representaciones a través de símbolos, la humanidad pudo distanciarse paulatinamente de los avatares de la mera subsistencia, al poder reconstruir lo acaecido, sopesar su significado y visionar lo posible. Distintos sistemas simbólicos se forjan a través de diversas expresiones de la sociedad y de la cultura; el juego infantil, la danza, la fiesta, las experiencias religiosas y deportivas, los ritos de paso alrededor de los ciclos vitales, entre otros, conforman sistemas simbólicos que participan en la construcción del sujeto y del colectivo del cual éste hace parte.

El juego y el arte (en sus distintas manifestaciones) son creaciones humanas que contribuyen a que las personas y sus comunidades puedan darle sentido a la compleja gama de interacciones que se dan entre ellas y el medio que les rodea. "Por la imaginación, la inteligencia se abre a nuevos horizontes. Es lo imaginario - no la razón, como decía Descartes-, el instrumento universal." (CHATEAU, 1976, p. 309). 
Infortunadamente, la sociedad capitalista moderna, en su afán por construir un sistema de pensamiento uniforme, que le facilitara el monopolio comercial, económico y político sobre distintos grupos sociales, pueblos y culturas, impuso la racionalidad en contraposición a la imaginación y la creatividad. No son gratuitos los enormes esfuerzos y recursos en sociedades industrializadas dedicados al estudio y estímulo de la creatividad, tendientes a contrarrestar los efectos castradores en la mayoría de la población de un sistema educativo altamente racional (STERNBERG, 1997; CSIKSZENTMIHALYI, 1998). Ó como expresara, uno de los teóricos hispanos más lúcidos sobre el juego y la creatividad:

Una sociedad eminentemente creadora vive en una atmósfera de símbolos y se nutre del poder simbólico de aquello que crea. Una sociedad estandarizada vive en régimen de préstamo de cuanto se dice y habla, y pierde gradualmente su potencialidad creadora, creadora de formas de vida, de acción, de arte. (LÓPEZ QUINTÁS, 1977, p. 18).

El juego, vehículo de toda suerte de actos humanos creadores, se inhibe particularmente en el proyecto de escuela para las clases trabajadoras y de minorías étnicas, orientado el currículo hacia la adquisición de meras habilidades para el trabajo asalariado. Los procesos de escolarización, que hemos heredado de esta racionalidad, privilegian una modalidad lógico-científica del pensamiento que se ocupa de causas generales y de su determinación, desplazando a un segundo plano o reprimiendo, modalidades narrativas y artísticas que procuran es darle significado a la experiencia (BRUNER, 1994).

Es la capacidad lúdica, considerada por los burócratas de la educación como "pérdida de tiempo", la que posibilita a los seres humanos crear "relaciones de interferencia que son fuente de luz intelectual y de belleza" (LÓPEZ QUINTÁS, 1977, p. 19):

[El juego es aquella] actividad corpóreo-espiritual libre, que crea bajo unas determinadas normas y dentro de un marco espacio-temporal delimitado un ámbito de posibilidades de acción e interacción con el fin no de obtener un fruto ajeno al obrar mismo, 
sino de alcanzar el gozo que este obrar proporciona, independientemente del éxito obtenido. [...] El juego es una actividad creadora de una trama de líneas de sentido que envuelven al mismo que las crea e impulsan su poder creador.(LÓPEZ QUINTÁS, 1977, p. 29)
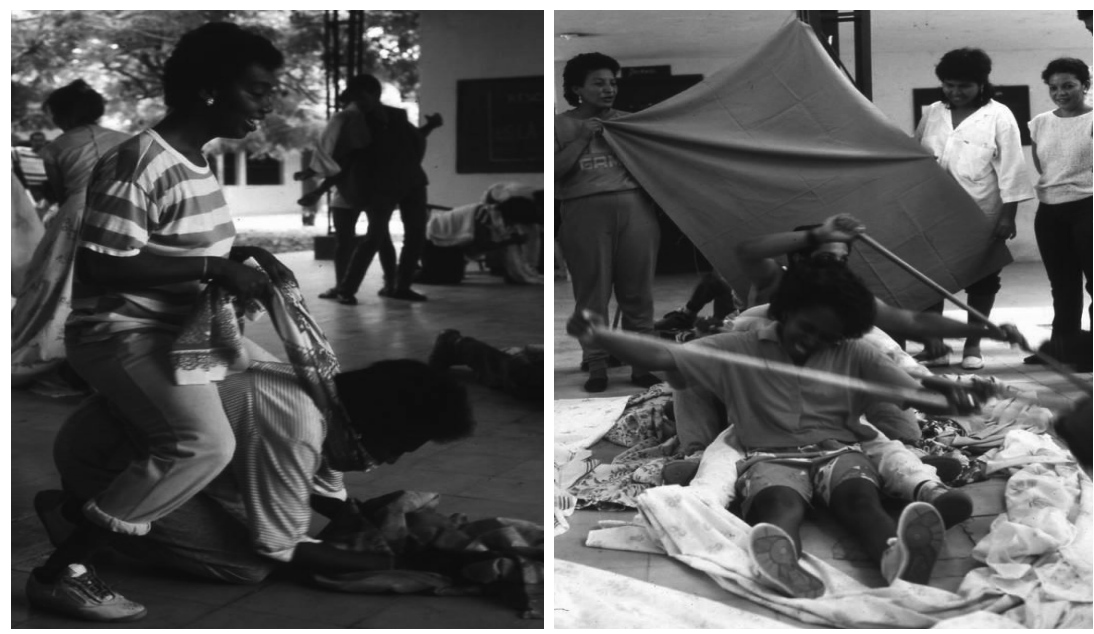

Figuras 16 y 17: Pedagogías creativas. Taller de juego y expresión creadora. Docentes El Bagre, Antioquia. Fotos: Zayda Sierra, 1989.

La violenta negación del juego por la cultura occidental cristiana se sustenta en la dicotomía cuerpo-espíritu y la idea profundamente arraigada de que la obtención de la vida eterna depende de la negación de todo aquello que sea expresión placentera del cuerpo; y el juego se caracteriza precisamente por producir y ser expresión de gozo. A su carácter libertario le es inherente la alegría y la risa:

La risa libera al aldeano del miedo al diablo. [...] La risa distrae, por algunos instantes, al aldeano del miedo. Pero la ley se impone a través del miedo, cuyo verdadero nombre es temor de Dios. [...] Y la risa sería el nuevo arte, ignorado incluso por Prometeo, capaz de aniquilar el miedo. (ECO, 1980, p. 490). 
Una pedagogía creativa debe fortalecer y recuperar el derecho de la gente a la expresión lúdica y artística para promover en cada ser, la familia, la escuela y la comunidad, el goce y disfrute de actos creadores que den sentido a su existencia y rompan con una vida condenada a la obtención de la mera subsistencia. El juego y el arte, en contraposición a la visión consumista que asume estas actividades humanas como mera diversión o entretenimiento (MONTAÑA, 1972), son actividades subversivas y libertarias, pues permiten no sólo aprender los saberes y las prácticas de tradiciones culturales propias, sino explorar alternativas a la existencia en un ambiente de menor riesgo, que difícilmente se intentarían por la presión del miedo a lo desconocido o a lo no autorizado (SIERRA; ROMERO, 2002).

La resistencia a la dominación de los pueblos originarios y afrodescendientes de Abya Yala ha sido posible por la pervivencia de sus saberes y prácticas lúdico-artísticas (ceremonias, rituales, fiestas, narrativas, cantos, pinturas, entre otros), así fueran permanentemente deslegitimadas. De allí la importancia de considerar en los currículos escolares y proyectos comunitarios la recuperación, recreación y resignificación de sus diversas manifestaciones culturales, sin negar espacios de intercambio y aprendizaje de experiencias creativas significativas con pueblos y culturas de otras latitudes.

\section{Preguntas para la reflexión y la investigación}

- ¿Qué significan el juego y la creatividad para diversos pueblos y culturas? ¿Qué caracteriza una persona, un proceso, un producto, una experiencia, un contexto como creativo? Valoraciones desde distintos momentos históricos, distintas culturas y el propio contexto de vida.

- ¿Cómo recuperar, estimular o fortalecer la motivación y el disfrute por aprender, así como la capacidad creadora y la imaginación de niñas, niños, jóvenes y adultos?

- Soñando mundos posibles. ¿Cómo propiciar saberes y acciones que permitan a las personas contribuir activamente con el mejoramiento de las condiciones de sus contextos de vida? 


\section{Pedagogía de la Madre Tierra}

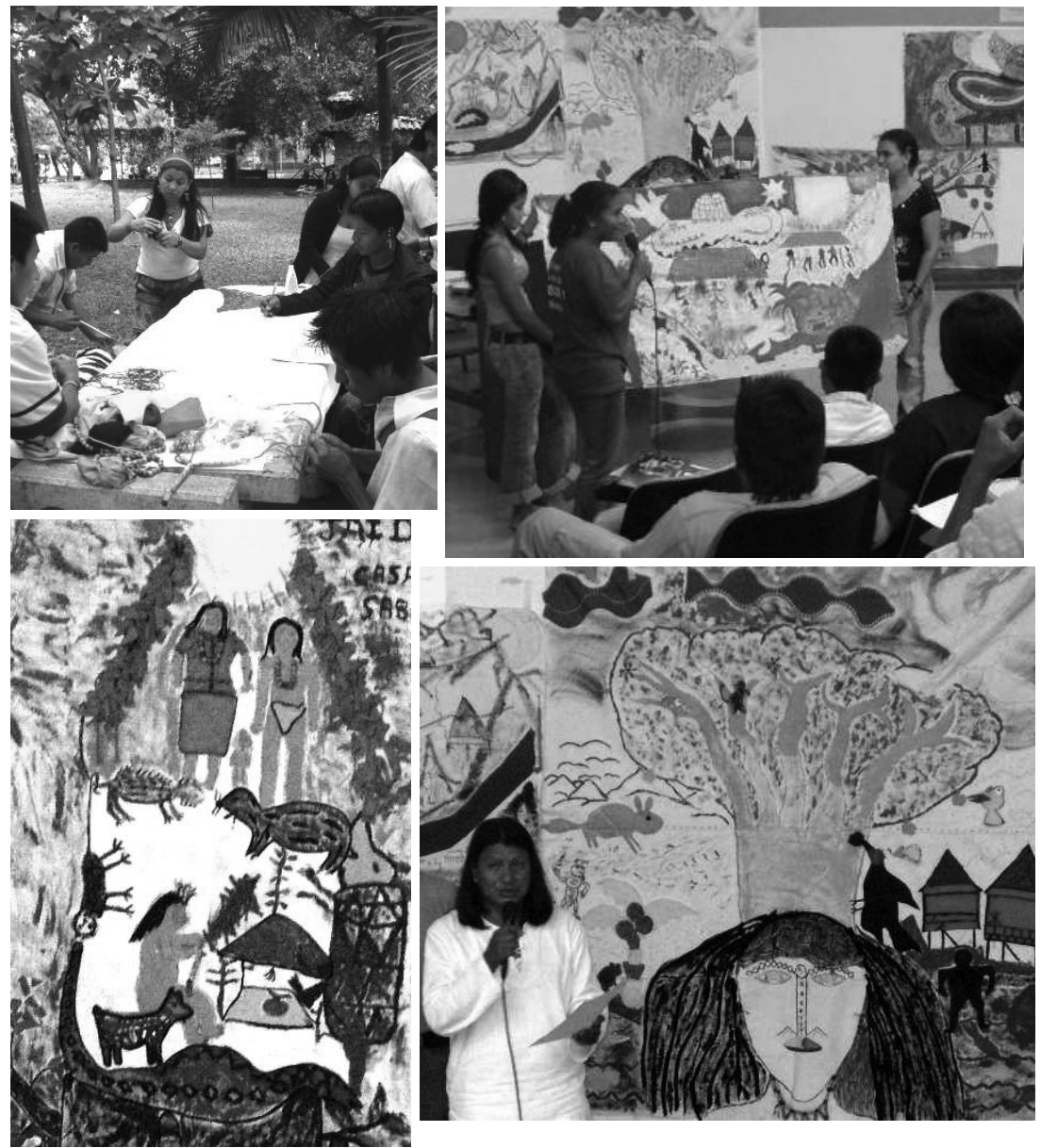

Figuras 18-21: Pedagogía de la Madre Tierra. Creación de murales sobre historias ancestrales. Diploma convenio Organización Indígena de Antioquia y Universidad de Antioquia. Fotos: Alba Rojas y Zayda Sierra, 2008.

Un esfuerzo de entretejer las anteriores perspectivas pedagógicas en una propuesta transformadora, en la búsqueda de hacer posible un mundo mejor, más justo y solidario entre las personas y pueblos, más respetuoso con la naturaleza y la vida en el planeta, ha sido la creación de una propuesta 
curricular hacia el cuidado de la Madre Tierra ${ }^{7}$. Es una invitación que hemos acogido con entusiasmo en nuestro colectivo de trabajo por permitirnos aprender y construir otras maneras de pensar la enseñanza y el aprendizaje, tanto en el contexto universitario y escolar como comunitario. Así explica esta filosofía nuestro colega Abadio Green, líder indígena y educador del pueblo Kunatule:

En diálogo con otros pueblos del mundo encontré que todos los pueblos indígenas de la tierra, todos, absolutamente todos, decimos que la tierra es nuestra madre, que todos los seres que habitamos somos sus hijas e hijos, porque dependemos de ella en cada instante de nuestras vidas, porque la estructura de nuestro cuerpo es igual al de la tierra. Nuestro hígado, nuestros pulmones, nuestros huesos, la sangre que corre por nuestras venas son iguales a las quebradas, a las montańas, a los diferentes ecosistemas que hay en la madre tierra, por tanto hay que protegerla, porque está tanto en nuestro propio cuerpo como en el aire que respiramos, el agua que bebemos, el sol que nos calienta y las plantas y animales que nos dan su sustento.

La educación oficial no sólo ha ignorado este vínculo sino que ha impuesto sus conocimientos por encima de la sabiduría ancestral de los pueblos originarios, y no ha podido, y le duele mucho reconocer la sabiduría de nuestros pueblos de Abya Yala. Todo el tiempo han tratado de quitar nuestra memoria, como han tratado de quitarnos a nuestra madre tierra, que es parte fundamental de nuestra espiritualidad, con esto pretenden continuar el saqueo de los recursos naturales y culturales que muchos pueblos han guardado celosamente para el bien de la humanidad. Una educación desde la Madre Tierra significa entonces aprender a prepararnos para salvarla, para que trabajemos juntos en su permanente cuidado y conservación.

Hoy más que nunca los mensajes de los pueblos antiguos toman el vigor, porque en los momentos actuales peligra la vida del planeta y de todos los 
seres que habitamos en ella por los innumerables megaproyectos de desarrollo que vienen ejecutando los países del "Primer Mundo". Por ello, hoy los pueblos indígenas quieren hablarle al mundo, para traer el mensaje de que todos los seres vivientes dependemos de ella, de la tierra: los animales, el aire, hasta los planetas, las estrellas dependen de ella. Por eso es grato escuchar voces de protestas en el mundo en defensa de la madre, en voces de no indígenas, sabios y sabias que también preocupados por el curso de la vida en la tierra, ponen un granito de arena a la paz del mundo. (GREEN, 2006, p. 131-141).

Otra búsqueda desde esta perspectiva pedagógica puede encontrarse en la proclama del movimiento liderado por los pueblos indígenas del Cauca (Colombia), "Liberar a la Madre Tierra":

Los pueblos indígenas sabemos, desde una memoria más profunda, desde nuestras historias más antiguas, desde nuestras experiencias diversas, desde los recuerdos y preceptos que están inscritos en nuestras lenguas, desde nuestros usos y costumbres y sobre todo desde el dolor, el maltrato y la incomprensión, que la historia desde la conquista, la historia del capital y de quienes a su nombre lo acumulan, es un proyecto de muerte que terminara por destruir la naturaleza toda, incluida la vida de los seres humanos. Para nosotros, la tierra es la madre y contra ella se comete un crimen del que vienen todos los males y miserias. Nuestra madre, la de todos los seres vivos, está sometida según la ley que se impone, tiene dueños, es propiedad privada. Al someterl, como propiedad para explotarla, le quitaron la libertad de engendrar vida y de proteger y enseñar el lugar, las relaciones y el tiempo de todo lo que vive. Le impiden producir alimentos, riqueza y bienestar para todos los pueblos y seres vivos. Los que se apropian de ella causan hambre, miseria y muerte que no deben ser. Le roban la sangre, la carne, los brazos, los hijos y la leche para establecer el poder de unos sobre la miseria de todos... Pero nosotros decimos, mientras sigamos 
siendo indígenas, o sea, hijos de la tierra, que nuestra madre no es libre para la vida, que lo será cuando vuelva a ser suelo y hogar colectivo de los pueblos que la cuidan, la respetan y viven con ella y mientras no sea así, tampoco somos libres sus hijos...

Por eso vamos a seguir recuperando las tierras. Por eso vamos a dejarla en libertad para convivir en ella y para defender la vida. Por eso, luchar por la tierra no es un problema ni un deber solamente de los indígenas, sino un mandato ancestral de todos los pueblos, de todos los hombres y mujeres que defienden la vida [...] (ASOCIACIÓN DE CABILDOS INDÍGENAS DEL NORTE DEL CAUCA, 2009).

La Pedagogía de la Madre Tierra nos invita entonces a aprender de miles de iniciativas alrededor del mundo (ecológicas, ambientalistas, feministas, campesinas, agroecológicas), orientadas a detener el deterioro a gran escala del planeta en este último siglo. Retomando estas sabias palabras que anónimamente circulan hoy por internet:

"Todo el mundo pensando en dejar un mejor planeta para nuestros hijos e hijas... ¿Cuándo pensaremos en dejar mejores hijos e hijas para nuestro planeta?"

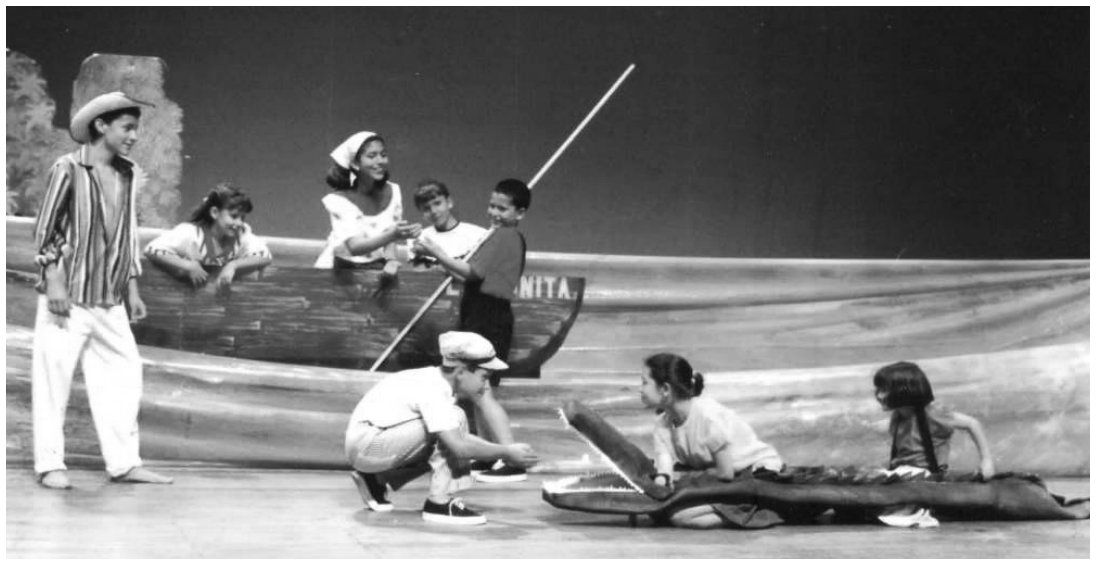

Figura 22: "El país pequeñito de los sueños perdidos". Teatro Infantil Bambalinas de la Universidad de Antioquia en Teatro Metropolitano, Medellín. Dirección artística: Zayda Sierra. Foto: Scott Stevens, 1994. 


\section{Preguntas para la reflexión y la investigación}

- ¿Por qué una pedagogía desde la Madre Tierra es una propuesta descolonizadora, crítica y creativa? ¿Cómo es considerada la naturaleza desde pedagogías ancestrales vs. coloniales y opresivas?

- Una pedagogía desde la Madre Tierra, ¿qué significa para la educación personal, familiar, escolar y comunitaria de pueblos indígenas y no indígenas?

- ¿Qué significa investigar desde una perspectiva de la Madre Tierra? ¿Qué paradigmas y metodologías se deben retomar, cambiar o crear, para que exista una aproximación al conocimiento más sensible y respetuoso con el cuidado de la naturaleza y todos los seres que la habitamos?

\section{Conclusiones}

Es primordial reconocer el intenso vínculo que existe entre colonialismo y modernidad para comprender cómo distintas violencias (económica, epistémica, étnica, de género, social y existencial) siguen presentes en la cotidianidad de nuestras vidas, en nuestras escuelas y universidades y cómo el quehacer pedagógico en el trabajo comunitario o escolar dista mucho todavía de lograr establecer una ruptura con el imaginario colonial.

La escuela que conocemos es de carácter homogenizante y hegemónico, regida por currículos diseñados en los centros de poder, que poco o nada reconocen las variadas problemáticas que enfrentan distintos grupos, personas y pueblos en su vida cotidiana. De allí la invitación, de acuerdo con Walsh (2005, p. 23) a pensar una educación que permita en nuestros diversos contextos a:

- aprender a descolonizar el pensamiento (descolonización en el sentido de dejar de ser colonizado) y

- mediante la confrontación de la deshumanización, el racismo y la negación de otros seres y campos del saber, ir desde otras lógicas y otros pensamientos hacia la construcción o creación de condiciones radicalmente diferentes de existencia (de-colonialidad). 
Quienes nos interesamos por una pedagogía que rompa con universalismos debemos preguntarnos por los distintos objetivos, espacios, tiempos y procesos que distintos grupos, pueblos o sociedades han destinado y destinan para la educación de su gente. Preguntarnos, por ejemplo:

- ¿Cómo se enseñaban y enseñan, se aprendían y aprenden, los saberes de los pueblos originarios y afrodescendientes de Colombia y Abya Yala, en distintos campos del conocimiento? (Pedagogías Ancestrales)

- ¿Qué saberes y prácticas pedagógicas europeas se impusieron para favorecer la conquista y colonización de los pueblos de Abya Yala y los pueblos esclavizados de África? (Pedagogías coloniales, opresivas y autoritarias)

- ¿Cómo distintas personas, grupos o pueblos en la región, el país y alrededor del mundo han venido enfrentando la opresión de sectores o culturas dominantes? (Pedagogías de Resistencia)

- ¿Cómo identificar de manera continua en el currículo, supuestamente neutral y universal, ideologías autoritarias, racistas, patriarcales, sexistas y clasistas? (Pedagogías críticas)

- ¿Cómo propiciar saberes y acciones que permitan a las personas contribuir activamente con el mejoramiento de las condiciones de sus contextos de vida? (Pedagogías creativas)

- ¿Qué implica una pedagogía que retome el cuidado de la naturaleza en la educación personal, familiar, escolar y comunitaria de pueblos indígenas y no indígenas? (Pedagogías desde la Madre Tierra)

Estas preguntas varían de acuerdo a los contextos de vida, es por ello la invitación a investigar de manera colaborativa distintas pedagogías que confluyen en el contexto de América Latina (ancestrales, opresivas y coloniales, de resistencia, críticas, creativas, de-coloniales, de la Madre Tierra) para comprender mejor como se entrecruzan, se oponen o dan nacimiento a nuevas propuestas.

Pedagogías desde la Diversidad Cultural es entonces un esfuerzo por construir alternativas educativas más adecuadas a los contextos locales - sin perder la perspectiva histórica global -, que cuestionen el carácter eurocéntrico, homogéneo y hegemónico, de la formación docente y los 
contenidos escolares, fortalezcan el sentido de comunidad y la resistencia a prácticas opresivas, y promuevan la generación de iniciativas orientadas a la defensa de la vida en todas sus diversas manifestaciones.

\section{Notas}

1 Las ideas que aquí se presentan, si bien son de mi exclusiva responsabilidad, emergen de muy diversas conversaciones en nuestro colectivo de trabajo. Mis reconocimientos a Alba Lucía Rojas, Alexandra Henao, Sabine Siniguí (Embera Katío), Hilda Mar Rodríguez, Leonardo Domicó (Embera Dóbida), Milton Santacruz (Kunatule), María Eugenia Morales (afrocolombiana) y muchas otras personas y comunidades que han apoyado con tanto cariño y compromiso los proyectos del Grupo de Investigación Diverser durante la década 1999-2009. Un reconocimiento también a las estudiantes de maestría Gloria Domicó (Embera Katío) y Gladis Yagarí (Embera Chamí) y al estudiante de doctorado Gustavo López, por sus inquietudes durante asesorías. Esta propuesta también se teje durante largas conversaciones sostenidas con Abadio Green (líder Kunatule, expresidente de la Organización Indígena de Antioquia-OIA, actual coordinador del Programa de Educación Indígena de la U de Antioquia) y Guzmán Cáisamo (líder Embera Dobida, rector del Instituto Departamental para la Educación Indígena-INDEI, de la Organización Indígena de Antioquia-OIA), ambos estudiantes del Doctorado en Educación, línea en Estudios Interculturales y coordinadores del colectivo de trabajo entre la OIA y la U de A para la creación de la propuesta "Licenciatura en Pedagogía de la Madre Tierra". Estas reflexiones se presentaron en el XII Congreso de la Association pour la Recherche Interculturelle (ARIC), "Diálogos Interculturales: descolonizar el saber y el poder", Universidad Federal de Santa Catarina, Florianópolis (SC, Brasil), junio 29 a julio 03 de 2009 y en el II Congreso Internacional de Investigación, Educación y Formación Docente, Facultad de Educación, Universidad de Antioquia (Medellín, Colombia), agosto 25 a 28 de 2009.

2 A través del estudio de epistemologías feministas, poscoloniales, ancestrales, de-coloniales; historia crítica de las ciencias, psicología histórico-socio-cultural, proyecto colonialidad/modernidad, entre otros aportes. 
3 Ver, por ejemplo, "Propuesta de reestructuración del campo de formación pedagógica en los programas de licenciatura de la Facultad de Educación”. Medellín: Universidad de Antioquia, Informe de Avance, contenidos de Historia del maestro e Historia de la infancia, mayo de 2007.

4 Sakla (sabio) del pueblo Kunatule, José David Jaramillo. (ENCUENTRO INTERCULTURAL... 2005).

5 Participante indígena. (ENCUENTRO NACIONAL... 2005).

6 Jimmy Cabrera, del pueblo Embera, estudiante de la Universidad Tecnológica del Chocó. (ENCUENTRO INTERCULTURAL... 2005).

7 Propuesta de creación de Licenciatura en Pedagogía de la Madre Tierra. Convenio entre la Organización Indígena de Antioquia y la Universidad de Antioquia (Programa de Educación Indígena y Grupo de Investigación Diverser de la Facultad de Educación). Proceso en construcción desde el año 2005 y aprobada por el Consejo Académico de la Universidad en septiembre de 2010. Mayor información en: < http://www. pedagogiamadretierra.org/ >.

8 Expresión anónima que circula en internet, citada por Coletivo socioambiental. Agradezco a Beleni Grando el envío de esta información. (TODO...2009).

\section{REFERENCIAS}

ASOCIACIÓN DE CABILDOS INDÍGENAS DEL NORTE DEL CAUCA. Libertad para la Madre Tierra. Cauca: Asociación de Cabildos Indígenas del Norte del Cauca, 2009. Disponible en: <http://www.nasaacin. org/libertad_madre_tierra_uno.html>. 2009. Consulta: 12 mar. 2009.

BARBOSA, Ana Mae. La educación y el desarrollo cultural y artístico: la educación artística en un museo de arte contemporáneo. In: JARAMILLO, M. A. (Ed.). Formación artística y cultural. Bogotá: Ministerio de Cultura, 2000. p. 142-149.

BRUNER, Jerome. Realidad mental y mundos posibles. Barcelona: Gedisa, 1994. 
CASTRO-GÓMEZ, Santiago. Ciencias sociales, violencia epistémica y el problema de la invención del otro. In: LANDER, E. (Ed.). La colonialidad del saber: eurocentrismo y ciencias sociales: perspectivas latinoamericanas. Buenos Aires: CLACSO-UNESCO, 2000. p. 145-163. CHATEAU, Jean. Las fuentes de lo imaginario. México: Fondo de Cultura Económica, 1976.

COMAS D’Argemir, Dolors. Economía, Cultura y Cambio Social. In: MARTÍNEZ, Joan Prat y Angel (Ed.). Ensayos de antropología cultural: homenaje a Claudio Esteva-Fabregat. Barcelona: Ariel, 1996. p. 104-113. CORONIL, Fernando. Naturaleza del poscolonialismo: del eurocentrismo al globocentrismo. In: LANDER, E. (Ed.). La colonialidad del saber: eurocentrismo y ciencias sociales: perspectivas latinoamericanas. Buenos Aires: CLACSO-UNESCO, 2000. p. 87-107.

CSIKSZENTMIHALYI, Mihaly. Creatividad: el fluir y la psicología del descubrimiento y la invención. Barcelona: Paidós, 1998.

ECO, Umberto. El nombre de la rosa. Barcelona: Lumen, 1980.

ENCUENTRO INTERCULTURAL DEL PROYECTO “CONOCER E INVESTIGAR DESDE LA PERSPECTIVA INDÍGENA Y UNIVERSITARIA", 2005, Antioquia. Notas durante el evento. Antioquia: Grupo Diverser/Colciencias y la Universidad de Antioquia. San Pedro de los Milagros, 2005.

ENCUENTRO NACIONAL EN EDUCACIÓN SUPERIOR INDÍGENA, 3., 2005, Medellín. Notas durante el evento. Medellín: Universidad de Antioquia, 2005.

GIROUX, Henry. Los profesores como intelectuales: hacia una pedagogía crítica del aprendizaje. Barcelona: Paidós, 1997.

GIROUX, Henry. Trabajo sobre estudios culturales en escuelas de magisterio.In: CANAAN, Joyce; EPSTEIN, Debbie (Ed.). Una cuestión de disciplina: Pedagogía y poder en los estudios culturales. Barcelona: Paidós, 1998. p. 47-64.

GREEN, Abadio. La educación desde la Madre Tierra: un compromiso con la humanidad. In: CONGRESO INTERNACIONAL DE 
EDUCACIÓN, INVESTIGACIÓN Y FORMACIÓN DOCENTE,1., 2006, Medellín. Memorias... Medellín: Facultad de Educación/ Universidad de Antioquia, 2006. p. 131-141.

LANDER, Edgardo. Ciencias sociales: saberes coloniales y eurocéntricos. In: E. Lander (Ed.). La colonialidad del saber: eurocentrismo y ciencias sociales: perspectivas latinoamericanas. Buenos Aires: CLACSOUNESCO, 2000. Buenos Aires: CLACSO-UNESCO, 2000. p. 11-41.

LÓPEZ Quintás, Alfonso. Estética de la creatividad: Juego, arte, literatura. Madrid: Cátedra, 1977.

MONTAÑA, Antonio. ¿Qué es el arte? Bogotá: Biblioteca Popular de Cultura, 1972.

NIETO, Mauricio. Remedios para el imperio: historia natural y la apropiación del nuevo mundo. Bogotá: ICANH, 2000.

\section{ORGANIZACIÓN NACIONAL INDÍGENA DE COLOMBIA.}

Territorios indigenas: identidad cultural y resistencia. Bogotá: ONIC/ Turdakke, 2002. p. 58-59. Textos: Kimy Pernía Domicó y Efrain Jaramillo.

PROPUESTA de reestructuración del campo de formación pedagógica en los programas de licenciatura de la Facultad de Educación. Medellín: Universidad de Antioquia, 2007. Informe de Avance, contenidos de Historia del maestro e Historia de la infância.

ROGOFF, Barbara. Aprendices del pensamiento: el desarrollo cognitivo en el contexto social. Barcelona: Paidós, 1993.

ROJAS, Axel (Comp.). Estudios afrocolombianos: aportes para un estado del arte. Popayán: Universidad del Cauca, 2004.

SÁENZ, Javier; SALDARRIAGA, Oscar; OSPINA, Armando. Mirar la infancia: pedagogía, moral y modernidad en Colombia: 1903-1946. Medellín: Colciencias, Foro Nacional por Colombia, 1997.

SÁENZ, Javier. Emociones, pasiones e imaginación: los adversarios de la moral, el orden y el progreso. In: ECHEVERRi, J. A. (Ed.). Encuentros pedagógicos transculturales: desarrollo comparado de las conceptualizaciones y experiencias pedagógicas en Colombia y Alemania. 
Medellín: Facultad de Educación/Universidad de Antioquia, 2001. p. 299-310.

SIERRA, Zayda. El país pequeñito de los sueños perdidos. Medellín: Teatro Infantil Bambalinas/ Coro Infantil de la Universidad de Antioquia, 1994. Audio casete.

. Estudiantes indígenas en la universidad: ¿Qué modelo educativo caracteriza su formación? Revista Colombiana de Educación, Santafé de Bogotá (Colom), n. 48, p. 177-195, enero/jul.2005.

; ROMERO, Angélica. ¿Investigar o construir nuevas realidades escolares? reflexiones a propósito de un proceso formativo e investigativo con docentes en San Onofre, Sucre- Colombia. Revista Colciencias: Ciencia \& Tecnología, Bogotá (Colom), v. 20, n. 4, p. 19-32, 2002.

STERNBERG, Robert. La creatividad en una cultura conformista: un desafío a las masas. Barcelona: Paidós, 1997.

TODO mundo 'pensando' em deixar um planeta melhor para nossos filhos.... Quando é que 'pensarão' em deixar filhos melhores para o nosso planeta? Bragança - Jornal Diário, Bragança, 11 ago. 2009. Coluna Ambiente em pauta. Disponible en: <http://www.bjd.com.br/detalhe_ coluna.php? codigo=2894.>. Consulta: 12 mar. 2009.

WALSH, Catherine.. Introducción: (re)pensamiento crítico y (de) colonialidad. In: . (Ed.). Pensamiento crítico y matriz (de)colonial. Quito: Universidad Andina Simón Bolívar/ Editorial Abya Yala, 2005. p. 13-36. 


\section{Pedagogies of cultural} diversity: an invitation for collaborative cross-cultural research

\section{Abstract}

Presenting a variety of reflections and questions that are the product of distinct experiences and projects in culturally diverse contexts, this article is an invitation to deepen in a collaborative form the distinct pedagogies that coexist in the Latin American context (ancestral, oppressive and colonial, resistant, critical, creative, de-colonial, of Mother Earth), which allow us to rethink the colonial and Eurocentric educational inheritance that still prevails in teacher education colleges. It constructs more creative proposals that have greater pertinence to the local contexts - without losing a global historic perspective - proposals that strengthen the recognition of cultural diversity, the sense of community and the ability to generate cross-cultural alliances for an existence on a just, equitable planet and in harmony with nature.

Key words: Teacher education - Latin America.

\section{Pedagogias desde a diversidade cultural: um convite à pesquisa colaborativa intercultural}

\section{Resumo}

Através de distintas reflexões e perguntas, produto de distintas experiências e projetos em contextos culturalmente diversos, este artigo é um convite para aprofundar de maneira colaborativa as diferentes pedagogias que coexistem no contexto da América Latina (ancestrais, opressivas e coloniais, de resistência, críticas, creativas, de coloniais, da mãe terra), que nos permita rever a herança colonial e eurocêntrica da formação docente que ainda prevalece nas faculdades de Educação. A partir dessa compreensáo, construir propostas educativas mais creativas e pertinente aos contextos locais. Sem perder a perspectiva histórica global, propostas que fortaleçam o reconhecimento à diversidade cultural, o sentido de comunidade e a capacidade de gerar alianças interculturais em direção a uma existência no planeta mais justa, equitativa e em equilíbrio com a natureza.

Palavras-chave: Educação - América Latina. Diversidade cultural - América Latina. Professores-Formação América Latina.

\section{Zayda Sierra}

E-mail: sierrazayda@yahoo.com. 